\title{
USING LEARNER-GENERATED DIGITAL MEDIA (LGDM) AS AN ASSESSMENT TOOL IN GEOLOGICAL SCIENCES
}

\author{
Jorge Reyna ${ }^{1}$, Finbarr G. Horgan², Daniel Ramp³ ${ }^{3}$ Peter Meier ${ }^{4}$ \\ ${ }^{1}$ Lecturer in Higher Education \\ ${ }^{2}$ Research Fellow, School of Life Sciences \\ ${ }^{3}$ Associate Professor, School of Life Sciences \\ ${ }^{4}$ Associate Professor, Dean of Teaching and Learning \\ Faculty of Science, University of Technology Sydney (AUSTRALIA)
}

\begin{abstract}
This study explores learner-generated digital media (LGDM) as an assessment tool in Geological Sciences. The aim was to engage students with the geology subject further and to develop their digital media literacies. For this purpose, a cohort of 97 students from the undergraduate Geological Processes subject (Autumn 2016) at the University of Technology Sydney, were randomly allocated to groups of 2-5 students. The students were asked to produce a five-minute digital media presentation on a chosen study topic. A lecture and workshop on digital media principles were delivered to prepare the students for the task early in the semester. Support and feedback were provided across the entire semester by the lecturer and digital media tutor through computer practicals and preparatory assignments. Group contribution was monitored using the SPARKPlus application. An online questionnaire was used at the end of the semester to gauge students' attitude towards LGDM. The survey assessed demographics, digital media support, attitudes toward the assignment, and the contribution of LGDM to skills development. Methodological triangulation was used with data sets from the questionnaire, group work and marks obtained. Our preliminary results indicate that students had a positive attitude towards LGDM as an assessment tool and that the assessment provided a novel opportunity for students to apply attributes such as 'creativity' to their learning experience of geology. Implications for teaching and learning are discussed.
\end{abstract}

Keywords: Digital presentations, learner-generated digital media, digital video in science education, digital storytelling.

\section{INTRODUCTION}

Geological Processes is a second year Science subject delivered during the Autumn semester at the University of Technology Sydney (UTS). Understanding landscape processes is an integral part of our future as we respond to environmental changes which have the potential to affect the places we live and the food we grow. Respect for and an understanding of environmental processes is an essential foundation for a career in science allowing students to contextualise their work.In this subject, students investigate the link between landforms and the processes by which they are created and change. The subject explores interactions between the hydrosphere, atmosphere and biosphere that drive these landscape-forming, or geomorphologic, processes. It examines how plant and animal adaptations are defined by both ancient and contemporary processes acting on landscapes and their abiotic components, thereby linking geology and biodiversity.

This subject does not belong to any specific program in the Faculty of Science at UTS, and over the years, subject coordinators have constantly changed from one semester to the next. These changes have delayed the subject from reaching maturity regarding pedagogical and instructional approaches. This situation can lead to challenges in ensuring student engagement throughout the subject. During the Autumn 2016 semester, a wide range of teaching and learning strategies were implemented to engage students with the subject further. The approaches included investigating geological concepts (related to plate tectonics, volcanoes and earthquakes) using data gathering from online open sources, and processing that data to develop literacy in Excel, Google maps and other standard science applications. This information was then used to develop projects with group and individual writing components. To further engage students with the subject, learner-generated digital media (LGDM) was implemented to communicate project outcomes and assess learning progress. This paper is a preliminary report on the intervention. 


\section{LITERATURE REVIEW}

The affordability of technology in conjunction with a broad range of software and applications, make feasible the production and hosting of digital video on the World-wide web via sharing services such as YouTube [1] and Vimeo [2]. Video production know-how is becoming a 'desirable' skill in the 21st century. Social software platforms such as Facebook [3], Instagram, and Vine [4] are examples of how people document their everyday activities using digital video.

Learning management systems (LMS) are designed to facilitate teaching activities and the delivery of content but do not foster student engagement and active learning [5]. In this regard, authentic assessments using LGDM can create an opportunity to upskill students in the use of technology and to help them 'learn by doing' and further engage with their subjects.

Digital media presentations in higher education have been reported to deploy content for blended learning [6] and, most recently, to 'flip' classrooms [7]. Learner-generated digital presentations emerged more than a decade ago in the field of education (pre-service teachers)[8-11]; and it has been incorporated recently into other disciplines. Digital presentations provide opportunities for the improvement of students' skills such as problem-solving, cooperative learning, critical thinking, and self-motivation [12].

By participating in the process of designing, creating, and presenting digital presentations a range of other skills are developed including digital, technological, visual, and global literacy [12-14]. Teachers can use these technologies as a valuable tool for motivation, collaboration, expression, and authentic assessment [15].

Learner-generated content has been shown to have the potential to add value not only in hands-on experience but also peer-driven learning [16]. In a related study by Reyna et al. (2016), second-year students of Pharmacology, assessed through LGDM found that the digital media assignment was engaging $(90 \%)$, fostered learning $(89 \%)$, and creativity $(91 \%)$. Seventy-four percent of students believed they had gained additional skills relevant to their future careers [17].

The positive impact of LGDM reported in the relevant literature was a stimulus to implement LGDM in the Geological Processes subject during Autumn 2016.

The aims of the study were:

(1) To engage students as co-creators of content to foster understanding of geological sciences and develop digital media literacies.

(2) To gauge students' attitudes towards LGDM assessments.

\section{METHODOLOGY}

This research used a mixed-methods approach [18], a procedure for collecting, analysing, and mixing both quantitative and qualitative data from each stage of the research process within a single study, to gain an in-depth understanding of the problem [19]. The data gathered came from three sources: (1) a student attitude questionnaire; (2) group contributions (SPARKPlus); and (3) the grades attained for the assignment. Methodological triangulation was applied to analyse the data sets, as the integration of multiple techniques increases the amount of data available and gains credibility for student responses [20].

The study was conducted during the Autumn Semester of 2016, in the science subject Geological Processes $(n=97)$. The students were randomly assigned to 21 groups (2-5 members), with group members working together through five $3 \mathrm{~h}$ computer practicals to advance their final projects. For the projects, the students researched seismic and volcanic activity in a chosen region (i.e., Australia and New Zealand, North America, Tonga, Hawaii, and so on). They used open-access data (including online materials available from Geoscience Australia, the Smithsonian Institution Global Volcanism Program, and the European-Mediterranean Seismological Centre) and displayed the data on interactive maps (Google maps). The students prepared an individual written report (2000 words) which was combined with reports from their group members to form a single continuous document. The written report indicated the students' understanding of plate tectonic theory and the effects of volcanic and seismic activity on biodiversity and human societies. Furthermore, it assessed students' capacities to interpret geological data and communicate scientific concepts in writing. Each group was asked to prepare a five-minute digital media presentation, based on elements of their report. Students 
received support in preparing their reports and media presentations during computer laboratory practicals.

This research followed the methodology described by Reyna et al. (2016) to implement the LGDM assessment.

\subsection{Pedagogy}

Active learning approaches drive pedagogy, students working in small groups, and 'learning by doing'. Some examples are problem based learning [21]; collaborative learning [22], cooperative learning [23], peer-assisted learning [24], and case studies [25]. These pedagogies can be used to design LGDM assessments as they promote student engagement with technology and develop research skills, collaborative working, problem-solving, technology and organisational skills [12]. The design of the LGDM followed a combination of these pedagogies to ensure an enhanced student learning experience.

\subsection{Student training}

We identified that digital media support for students is essential. Training on how to create effective digital presentations was planned and delivered to the students. Topics covered in the digital media lecture were: (1) digital presentation types; (2) video quality and resolution; (3) audio recording; (4) video framing; (5) content creation for digital presentations; (6) using colour effectively; (7) typography; (8) tools available to produce digital presentations, and; (9) how to develop a storyboard. The training was conducted with a combination of lectures and a workshop early in the semester.

\subsection{Hosting of video}

The video hosting service was determined before designing the assessments. Digital presentation assignments should be accessible to all the students as it will foster discussion and consideration of ideas. The use of video sharing services (YouTube) was considered for students to upload their digital media file. We created a classroom account and shared the details with the students. Students could see each group's work and comment if necessary. The shareable nature of YouTube is a desirable feature as the literature reports that students take pride in their work when it is shared and put more effort into the task at hand [26]. Furthermore, an accessible YouTube account represents a novel forum to receive feedback from the tutors and peers.

\subsection{Marking scheme}

It is important to consider the weighting of the activity since preparation of LGDM can be timeconsuming. It is recommended to have at least $20 \%$ of the total subject mark devoted to this assignment. Additionally, the use of rubrics is highly encouraged as this helps the students to focus on the important elements of the task and will make marking more objective, particularly if several tutors/instructors are involved in the marking process [27]. The LGDM assessment constituted $20 \%$ of the final subject mark (10\% for a subject related Powerpoint Presentation and $10 \%$ for the final derived video presentation). A marking rubric was designed before the semester started, and was provided and explained to the students during the workshop. The marking criteria included accuracy and completeness of information, use of digital media to enhance communication of the topic, creativity (how the presentation enhances the topic), understanding of the underlying scientific principles, and the quality of the research using available resources (textbooks, published papers, etc.).

\subsection{Group contribution}

The contribution of individual members of each group to their project was assessed. A suitable approach in this case was self and peer-assessment [28-30]. A rubric related to the students' contributions to group work was designed and a peer review application used (SPARKPlus) to allow students to rate each other's contributions to the project. Using such a tool helped to identify free riders and non-contributors and to correct their marks accordingly.

Group contribution (SPARKPlus) data was gathered from the application for further analysis. Based on the ratings of each team member against the criteria, SPARKPlus automatically produced the selfand peer-assessment factor (SPF). This factor is an individual performance factor that measures how the group overall viewed the individual contribution of each team member. The SPF factor is proportional to the average of total ratings of all group members divided into the total ratings of team members. This SPF factor was used to convert group project marks into an individual mark using the formula, individual mark = group mark $x$ individual's SPF. For example, if a group receives 80/100 for 
their project and a student in that group receives a SPF factor of 0.9 for his/her contribution (reflecting a lower than average team contribution), the student will receive an individual mark of 72 . Individual mark $=80 \times 0.9=72$.

An SPF $>1$, means that that student's contribution was greater than the average. In contrast, an SPF $<1$ means that that student's contribution was less than average. The maximum grade the students could get for the LGDM assignment was set at ten following the subject outline. At the end of the marking period, the grades attained were gathered from the grade centre on the learning management system (LMS).

\subsection{Feedback}

When implementing learning designs that use innovative ways to assess students, it is crucial to provide targeted, specific and timely feedback. The purpose of feedback is to reduce discrepancies between understanding, performance, and the learning objectives [31]. Students received formal feedback at a storyboarding workshop and throughout the semester during lectures and computer practicals.

\subsection{Evaluation}

Evaluation is a critical component of any educational intervention. The purpose of evaluation is to generate data that will help to improve the activity in the next iteration. The sources of data used in this research were: student perceptions (via an online survey), student assessment performance (grade attained) and student actions (group contribution) [32].

To evaluate student attitudes towards LGDM as an assessment tool, an online questionnaire (Likert scale) and five open-ended questions were developed, and students were asked to participate on a voluntary basis. The survey included sections on; (1) demographics; (3) digital media support (lectures and workshop); (4) the assignment; (5) the contribution of LGDM to skill development; and (6) an open-ended question for additional comments (Table 1).

Table 1: Online questionnaire to gauge student's attitude towards the digital media assignment

\begin{tabular}{|l|}
\hline Demographics \\
\hline Gender \\
Age bracket \\
Level of education \\
English as an additional language \\
\hline Digital media support \\
\hline The digital media lecture was engaging \\
I applied concepts from the lecture to my assignment \\
I need a better understanding of digital media principles \\
I will recommend that my peers attend this lecture \\
I used a storyboard to structure my project \\
Overall the technical support to complete my project was good \\
\hline The assignment \\
\hline I believe instructions on the assignment were clearly provided \\
The timeframe to complete the project was good \\
I understand the importance of communicating concepts/ideas in the digital world \\
Overall I was happy about the digital media assignment \\
\hline Digital media contribution to skill development \\
\hline The digital media helped me to develop critical thinking skills \\
The digital media helped me to develop communication skills \\
The digital media helped me to work as part of a team \\
The digital media helped me to exercise my creativity \\
\hline
\end{tabular}

\section{RESULTS AND DISCUSSION}

We received a high response rate for the online questionnaire, 84 out of 98 students completed the survey ( $86 \%$ response rate). We requested participation on a volunteer-basis using announcements inside the LMS. Two reminders were sent a week apart. The responses rates are presented in the following sections. 


\subsection{Demographics}

Regarding demographics, fifty-six percent of students were males while 44 percent were females. Most of the students were between 18-29 years old (97.6\%). Their level of education was high school graduate $(78.6 \%)$, and a small percentage had English as an additional language (11.9\%). Detailed demographics are presented in Table 2.

Table 2: Demographic characteristics of participants $(N=84)$

\begin{tabular}{|l|l|l|}
\hline Characteristic & $\mathbf{n}$ & $\%$ \\
\hline Gender & 47 & 56 \\
Female & 37 & 44 \\
\hline Age bracket & & \\
$18-29$ & 82 & 97.6 \\
$30-49$ & 2 & 2.4 \\
$50-64$ & 0 & 0 \\
65 and over & 0 & 0 \\
\hline Level of education & & \\
High school graduate & 66 & 78.6 \\
Some college & 8 & 9.5 \\
Trade/technical/vocational training & 3 & 3.6 \\
College graduate & 1 & 1.2 \\
University degree & 6 & 7.1 \\
\hline English as an Additional Language (EAL) & & \\
Yes & 10 & 11.9 \\
No & 74 & 88.1 \\
\hline
\end{tabular}

\subsection{Digital media support}

The responses in this section showed a positive attitude towards the support provided to the students. Eighty-eight percent of the students found the digital media lecture engaging while $93 \%$ applied the concepts from the lecture to their assignments. Eighty-six percent of the students used a storyboard to structure their projects. Storyboards are important to ensure the production of a quality digital artefact [33] but also to develop conceptual skills for digital media production [34]. Ninety-five percent of students agreed they need a better understanding of digital media principles. We are conscious of this, as explaining the principles within an hour lecture can be overwhelming. That is the reason why we only covered the basics of digital media theory (section 3.2). Extensive practice will be required to understand and apply these principles further [35]. We hope the students will further develop these skills in additional subjects across their studies. Seventy-three percent of students indicated that they would recommend the digital media lecture to their peers while $90 \%$ thought the support provided was good (Graph 1).

The results are in agreement of what we reported in 2016 using LGDM in a cohort of pharmacology students [17]. The literature in the field of digital media as an assessment tool does not report training to students in digital media principles. Ths may be because previous studies used digital media opportunistically as a pedagogical agent [36]. Our approach is based on a pedagogical and digital media agent. As future scientists, our students will need to be able to produce effective digital media 
for journals, grants proposal and, in some cases to educate the general public. That is why it is desirable to teach them digital media principles.

Graph 1: Student perceptions of digital media support

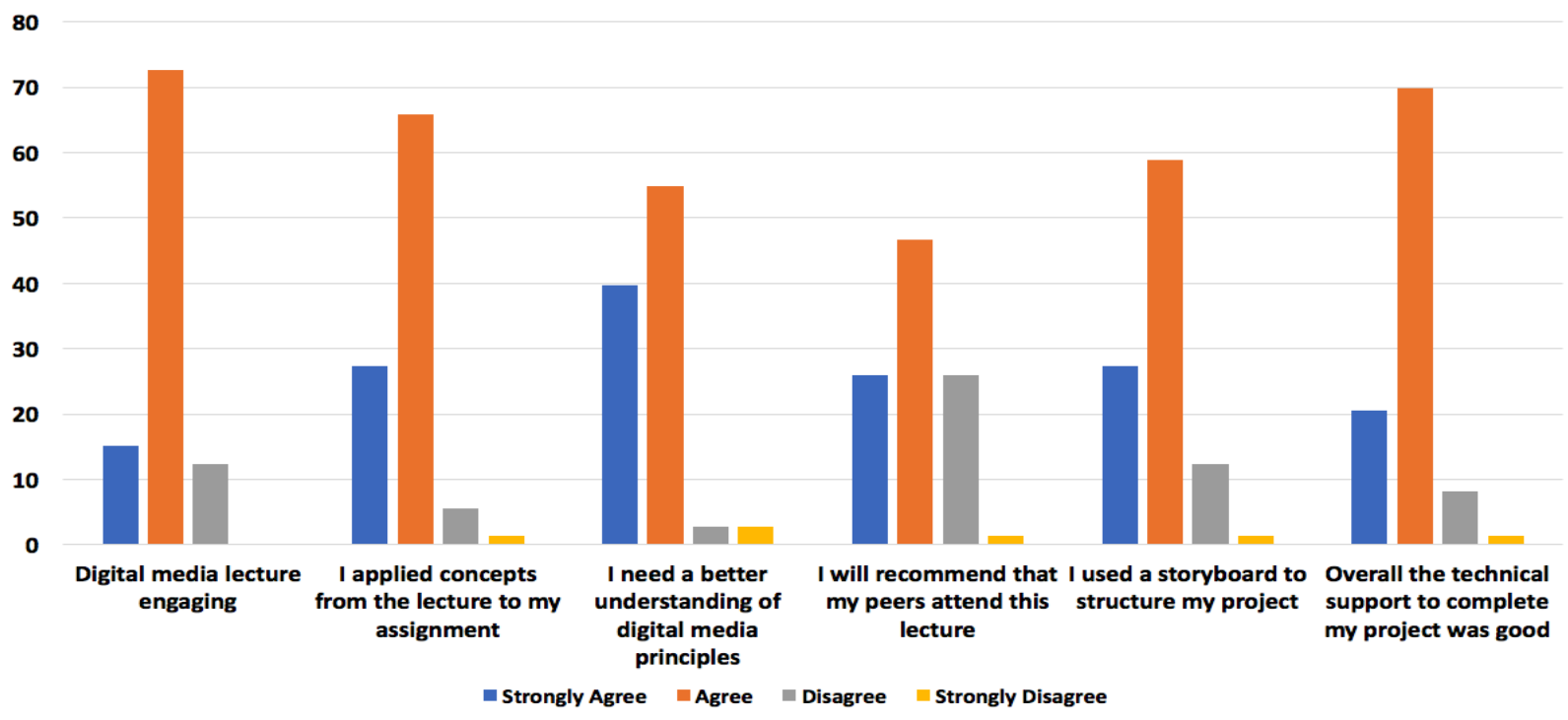

\subsection{About the assignment}

An important aspect that is missing in current literature is an understanding of students' perceptions of digital media assignments. Seventy-five percent of the students in the present study reported that the instructions for the assignment were clearly provided. Communicating the task to the students is important as it has been reported they students may become anxious about digital media assignments [37]. Explaining the assignment at the beginning of the semester and providing early feedback on project ideas will have a positive impact on student engagement. Ninety-five percent of students thought the timeframe to complete the assignment was adequate. We are conscious that digital media assignments can be time-consuming, that is the reason why we allocated groups of 4-5 students (only one group had $<4$ members). Eighty-seven percent of the students were happy about the digital media assignment (Graph 2). These results are in accordance to what we reported in 2015 based on responses from pharmacology students [17].

All student respondants $(100 \%)$ agreed that it is important to know how to communicate concepts/ideas in the digital world. This attitude among students is notworthy as it can act as a motivational factor for students to self-regulate their learning using digital media [38].

Graph 2: About the digital media assignment

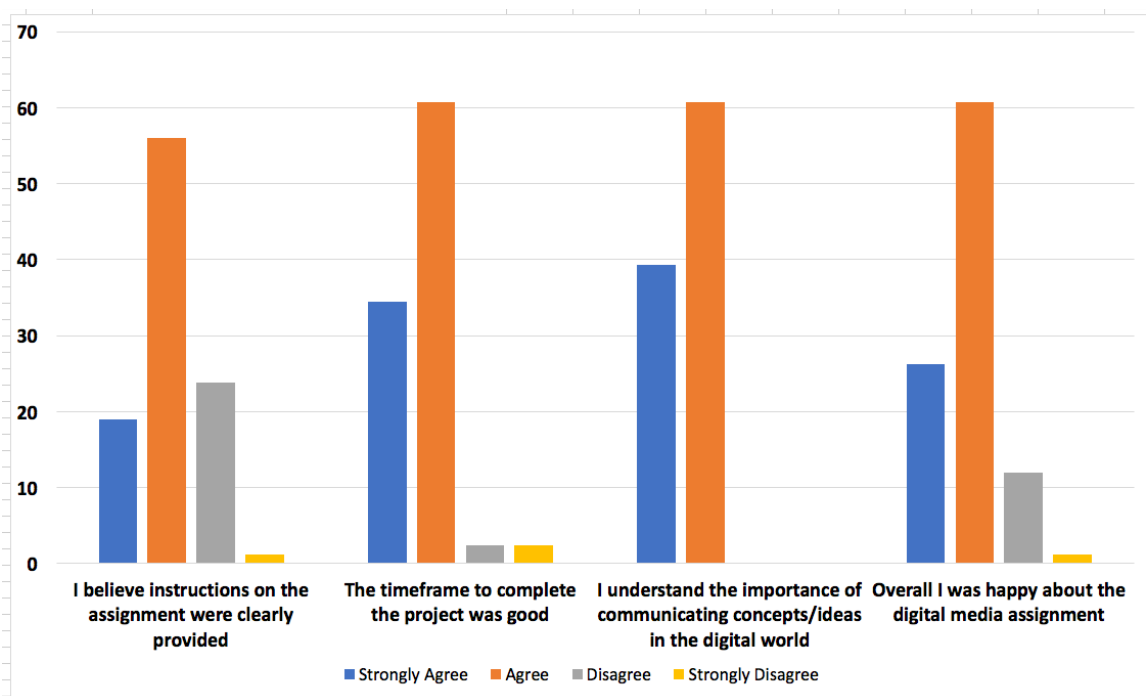




\subsection{Digital media contribution to skills development}

The students' perceptions of competencies learnt through the digital media assignment were also positive. Seventy-three percent of students thought they developed critical thinking skills, $85 \%$ communication skills and $86 \%$ teamwork skills. Ninety-three percent of students thought the digital media assignment helped them to exercise their creativity (Graph 3).

Teamwork sometimes can be challenging, and students often do not enjoy it [39]. We believe the nature of the task (collaborative work) and the use of SPARKPlus made group work a better experience for the students. It will be required in the next iteration of this research to gain an in-depth understanding of how students work together in digital media assignments. Further information can be gathered by focus groups and individual interviews.

Graph 3: Digital media assignment contribution to skill development.

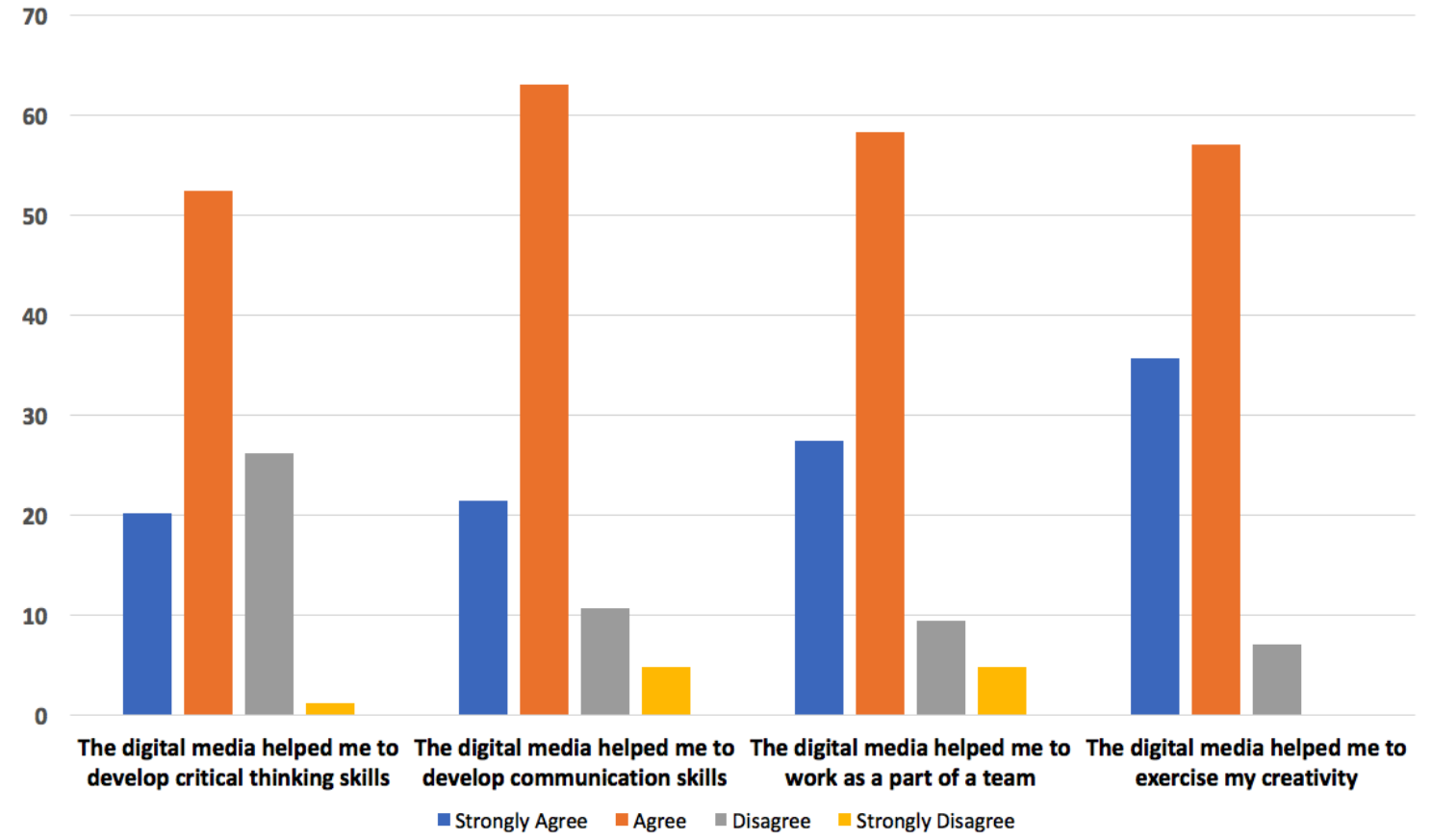

\subsection{Additional comments}

In response to the open-ended question, additional positive and negative comments from the students are presented below. The positive comments highlighted creativity, teamwork, new skills and freedom to choose the topic of the digital media project:

Learning how to use digital media, being creative and working together in a team made this assignment interesting.'

'I liked the learning experience and opportunity to learn something new that wouldn't necessarily be provided in a class subject like geological processes. I enjoyed this learning curve as it has provided me skills to use in the future whether it be for future classes or projects in the workforce, I have the basic skills to make a digital presentation.'

'It was pretty much up to our own choosing of the topic. So, we choose something that really interested us and it was so much easier to create an assignment like that'

The negative comments highlighted confusion, lack of knowledge, and the time-consuming nature of the digital media task.

'It was difficult to gauge a standard for the digital presentation and to understand what we were actually meant to include'.

'The lack of knowledge I had, when using video software'

'Just very time-consuming at an extremely busy time of semester'. 


\subsection{Group contribution}

Group contribution was assessed using the SPARKPlus application; data was collected for the entire cohort of students as the SPARKPlus task was compulsory ( $\mathrm{N}=97)$.

Table 3: SPF factor for group contribution on the digital media task

\begin{tabular}{|l|l|l|l|l|l|}
\hline Contribution & $\%(\mathbf{n})$ & Min & Max & Mean & S.D. \\
\hline $\begin{array}{l}\text { Optimum } \\
(\text { SPA }>1.0)\end{array}$ & $60(57)$ & 1.01 & 1.18 & 1.05 & 0.05 \\
\hline $\begin{array}{l}\text { Acceptable } \\
(\text { SPA }=0.9-1.0)\end{array}$ & $30(29)$ & 0.90 & 1.00 & 0.97 & 0.03 \\
\hline $\begin{array}{l}\text { Poor } \\
(\text { SPA }<0.90)\end{array}$ & $10(10)$ & 0.19 & 0.89 & 0.68 & 0.22 \\
\hline
\end{tabular}

Ninety percent of students worked effectively in their groups (60\% optimum $+30 \%$ acceptable), and $10 \%$ performed poorly. The peer-assessments (SPARKPlus) suggested that most students actively participated in the assignment.

We had qualitative data on group contribution that we are currently analysing to explain the poor performance of $10 \%$. So far, the data indicates students did not come to meetings, did not answer emails, or did not contribute to the project. These findings are in agreement with findings from pharmacology students in 2015 where $6 \%$ of students performed poorly in the group work [40]. The literature on LGDM as an assessment tool does not report group dynamics and how students work in LGDM is not well documented in the current literature. We are planning to run focus groups and individual interviews in 2017 to gain an in-depth understanding of how students work together on a digital media task.

\subsection{Student marks}

Students were marked using a rubric for the assignment. The document was available to the students through the LMS. Students predominantly used blended media in the LGDM presentations, with a few groups opting for videoed sketches or voice-overs of PowerPoint presentations. The information presented was consistently accurate and well-researched and was presented using documentary, mockumentary and humorous approaches. Several groups included animated cartoons, including one group that applied available animation applications (i.e., GoAnimate). Students therefore scored highly in the assignment (Graph 4).

Graph 4: Results from the assignment $(n=97)$ after correction using peer assessment scores (SPARKPlus). All but one student passed the assignment with the majority achieving distinction $(>8)$.

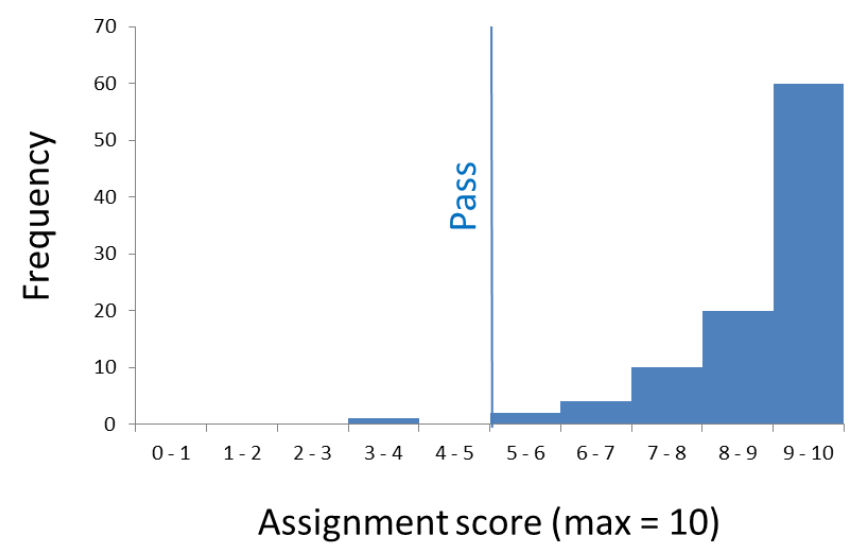




\section{CONCLUSION}

Preliminary data presented from the online questionnaire, group work contribution (SPARKPlus) and grades attained showed that LGDM has great potential to engage students in learning geological concepts and in developing their digital media literacies. The training provided was well received and students were keen to learn digital media creation skills. The entire cohort of students indicated that they believe it important to be able to communicate concepts and ideas in the digital world, this represents a considerable motivation (self-efficacy, goal orientation and task value) to succeed in the digital media assignment. Group work in digital media seemed to work well for $90 \%$ of the students in this cohort.

The current limitation of this research is related to lack of focus groups and student interviews. The ways by which students organise group work and their division of roles and task strategies are unknown; but will be assessed during the next phase of this research. We are planning to apply selfregulation theory and an understanding of motivational factors to gain an in-depth understanding of students learning when using digital media as an assessment tool.

We firmly believe that the key to the success of this intervention was the support we gave to students in subject content and digital media during the semester.

\section{ACKNOWLEDGEMENTS}

The authors thank the 2016 students of Geological Processes for participating in this research and for their feedback on the experience.

\section{REFERENCES}

[1] Snelson, C., YouTube across the disciplines: A review of the literature. MERLOT Journal of Online Learning and Teaching, 2011.

[2] Sturges, M. and J. Reyna. Use of Vimeo on-line video sharing services as a reflective tool in higher educational settings: A preliminary report. in ASCILITE-Australian Society for Computers in Learning in Tertiary Education Annual Conference. 2010.

[3] West, L.E., Facebook sharing: A sociolinguistic analysis of computer-mediated storytelling. Discourse, Context \& Media, 2013. 2(1): p. 1-13.

[4] Salomon, D., Moving on from Facebook Using Instagram to connect with undergraduates and engage in teaching and learning. College \& Research Libraries News, 2013. 74(8): p. 408412.

[5] Quinton, S., Principles of Effective Online Learning Design, in Toward the Future of Technology Enhanced Education: Ubiquitous Learning and the Digital Native, A.a.M.S. Graz University of Technology, M.A., University of Zurich, Switzerland (Editors), Graz University, Austria, Editor. 2009, IGI Global: Austria.

[6] Bonk, C.J. and C.R. Graham, The handbook of blended learning: Global perspectives, local designs. 2012: John Wiley \& Sons.

[7] Bergmann, J. and A. Sams, Flip your classroom: Reach every student in every class every day. 2012: International Society for Technology in Education.

[8] Crean, D., QuickTime streaming: a gateway to multi-modal social analyses. e-Xplore, 2001.

[9] Hoban, G. and W. Nielsen, Learning Science through Creating a 'Slowmation': A case study of preservice primary teachers. International Journal of Science Education, 2013. 35(1): p. 119146.

[10] Kearney, M. and S. Schuck. Students in the director's seat: Teaching and learning with student-generated video. in Proceedings of Ed-Media 2005 World Conference on Educational Multimedia, Hypermedia and Telecommunications. 2005. Citeseer.

[11] Ludewig, A., iMovie. A student project with many side-effects. e-Xplore, 2001.

[12] Malita, L. and C. Martin, Digital storytelling as web passport to success in the 21st century. Procedia-Social and Behavioral Sciences, 2010. 2(2): p. 3060-3064. 
[13] Frazel, M., Digital storytelling guide for educators. 2010: International Society for Technology in Education Washington, DC.

[14] Robin, B.R., et al., Preparing for the changing role of instructional technologies in medical education. Academic Medicine, 2011. 86(4): p. 435-439.

[15] Hazzard, E., Screencasts are a valuable tool for motivation, collaboration, expression, and authentic assessment. The Science Teacher, 2014. 81(3).

[16] Berardi, V. and G.E. Blundell, A learning theory conceptual foundation for using capture technology in teaching. Information Systems Education Journal, 2014. 12(2): p. 64.

[17] Reyna, J., et al., Implementing Digital Media Presentations as Assessment Tools for Pharmacology Students. American Journal of Educational Research, 2016. 4(14): p. 983-991.

[18] Tashakkori, A. and C. Teddlie, Sage handbook of mixed methods in social \& behavioral research. 2010: Sage.

[19] Creswell, J.W., Qualitative inquiry and research design: Choosing among five approaches. 2012: Sage.

[20] Gorissen, P., J.V. Bruggen, and W. Jochems, Methodological triangulation of the students' use of recorded lectures. International Journal of Learning Technology, 2013. 8(1): p. 20-40.

[21] Hmelo-Silver, C.E., Problem-based learning: What and how do students learn? Educational psychology review, 2004. 16(3): p. 235-266.

[22] Goodsell, A.S., Collaborative learning: A sourcebook for higher education. 1992.

[23] Millis, B.J. and P.G. Cottell Jr, Cooperative Learning for Higher Education Faculty. Series on Higher Education. 1997: ERIC.

[24] Topping, K. and S. Ehly, Peer-assisted learning. 1998: Routledge.

[25] McDade, S.A., Case study pedagogy to advance critical thinking. Teaching of psychology, 1995. 22(1): p. 9-10.

[26] Kearney, M., Learner-generated digital video: Using Ideas Videos in Teacher Education. Journal of Technology and Teacher Education, 2013. 21(3): p. 321-336.

[27] Spires, H. and G. Morris, New Media Literacies, Student Generated Content, and the YouTube Aesthetic, in EdMedia: World Conference on Educational Media and Technology 2008, J. Luca and E.R. Weippl, Editors. 2008, Association for the Advancement of Computing in Education (AACE): Vienna, Austria. p. 4409-4418.

[28] Hanrahan, S.J. and G. Isaacs, Assessing self-and peer-assessment: The students' views. Higher education research and development, 2001. 20(1): p. 53-70.

[29] Willey, H., et al., SPARK-plus self and peer assessment guide $v$ 1.7. 2009, Sydney: University of Technology Sydney.

[30] Willey, K. and A. Gardner, Investigating the capacity of self and peer assessment activities to engage students and promote learning. European Journal of Engineering Education, 2010. 35(4): p. 429-443.

[31] Hattie, J. and H. Timperley, The power of feedback. Review of educational research, 2007. 77(1): p. 81-112.

[32] Phillips, R., C. McNaught, and G. Kennedy, Evaluating e-learning: Guiding research and practice. 2012: Routledge.

[33] Stockman, S., How to Shoot Video That Doesn't Suck: Advice to Make Any Amateur Look Like a Pro. 2011: Workman Publishing.

[34] Hashimoto, A. and M. Clayton, Visual Design Fundamentals: A Digital Approach, Charles River Media. Inc., Rockland, MA, 2009.

[35] Malamed, C., Visual Design Solutions: Principles and Creative Inspiration for Learning Professionals. 2015: John Wiley \& Sons. 
[36] Buckingham, D., Media education goes digital: an introduction. Learning, Media and Technology, 2007. 32(2): p. 111-119.

[37] Pearce, K.L. Undergraduate creators of video, animations and blended media: The students' perspective. in Proceedings of The Australian Conference on Science and Mathematics Education (formerly UniServe Science Conference). 2014.

[38] Zimmerman, B.J. and D. Schunk, Motivational sources and outcomes of self-regulated learning and performance. Handbook of self-regulation of learning and performance, 2011: $p$. 49-64.

[39] Taylor, A., Top 10 reasons students dislike working in small groups... and why I do it anyway. Biochemistry and Molecular Biology Education, 2011. 39(3): p. 219-220.

[40] Reyna Zeballos, J.L., et al., Implementing Digital Media Presentations as Assessment Tools for Pharmacology Students. American Journal of Educational Research, 2016. 4(14): p. 983991. 